\title{
Investigation and Analysis on the Postgraduate Entrance Examination for Undergraduate Students from Private Colleges and Universities
}

\author{
Shaohong Chen1, Shaomei Fang2, Yan'e Zhang1* \\ ${ }^{1}$ Institute of Foreign Languages, Guangzhou Huashang College, Guangzhou 511300, Guangdong Province, China \\ ${ }^{2}$ College of Mathematics and informatics College of Software Engineering, South China Agricultural University, Guangzhou \\ 510640, Guangdong Province, China \\ *Corresponding author: Yan'e Zhang, muyon77555@163.com

\begin{abstract}
Students from private undergraduate universities were included in this study as research subjects. Questionnaires were distributed to the students to collect information in order to keep abreast of students' motivation, preference, preparation and plan, encountered difficulties and adjustments made, demands, as well as other aspects about their postgraduate entrance examination. The results showed that students from private universities have clear motivation for their postgraduate entrance examination, but there are some problems, such as the lack of scientific choices, long preparation time, more challenges, and lack of school support. In view of these problems, this study offers countermeasures and suggestions for these students and relevant schools.
\end{abstract}

Keywords: Private colleges and universities; Postgraduate entrance examination; Countermeasures and suggestions

Publication date: November 2021; Online publication: November 30, 2021

\section{Introduction}

With the popularization of higher education, having just a degree is no longer the ultimate goal of education. The rising standard of the elite class is guiding the direction of postgraduate entrance examination for college students, and postgraduate talents have become an impetus for promoting social progress ${ }^{[1]}$. In recent years, China's demand for postgraduate talents is growing, and the number of postgraduate candidates has increased significantly ${ }^{[2]}$. According to the data from the Ministry of Education of the People's Republic of China, the number of master's degree applicants in 2021 is 3.77 million, an increase of 360,000 over the previous year and a record high ${ }^{[3]}$. In recent years, undergraduate students are actively participating in the postgraduate entrance examination; the number of applicants and enrollment are increasing year by year. Relevant surveys have shown that $54.96 \%$ of them have intention to sit for the postgraduate entrance examination, $22 \%$ have no intention, and $23.04 \%$ are still hesitant. Moreover, more than half of undergraduate students from private universities are inclined to sit for the examination ${ }^{[4]}$. This study investigates the current situation and existing deficiencies of the postgraduate entrance examination for undergraduate students from private universities and offers countermeasures for improvement, so as to provide reference for students' further studies and schools' personnel training.

\section{Research and design}

\subsection{Designing the questionnaire}

According to the research demands, this study adopted the method of questionnaire survey, and the 
questionnaire was designed on the basis of relevant research at home and abroad pertaining to the postgraduate entrance examination of students from private undergraduate universities.

The questionnaire consists of five sections. The first section includes basic information such as gender, grade point, and motivation for the postgraduate entrance examination, with a total of 3 questions. The second section is regarding the preference and reason for the examination, including the selection of college and specialty as well as the reasons for it, with a total of 4 questions. The third section includes students' preparation for the examination, such as the determination of the exam time, the time required, and the daily review time, with a total of 3 questions. The fourth section includes the difficulties encountered and adjustment made in the process of sitting for the examination, such as the obstacles, difficult subjects, views on the test, and how to self-adjust, with a total of 4 questions. The fifth section includes students' demands, such as the choice of preparation methods as well as the guidance and support from their schools, with a total of 4 questions.

\subsection{Distributing and collecting the questionnaires}

The research included those who had graduated in 2020 and 2021 from Guangzhou Huashang College and had taken the postgraduate entrance examination. The participants answered the questions through an electronic questionnaire. A total of 180 valid questionnaires were recovered, of which $100 \%$ were available. The sample covered students from various universities, ensuring the representativeness and authenticity of this study.

\section{Results}

\subsection{Basic information and motivation for the postgraduate entrance examination}

A total of 180 valid questionnaires were collected in this study. Among all the respondents, the proportion of male students was $38.89 \%$, and that of female students was $61.11 \%$; the proportion of grade points above 4.0 was $6.67 \%, 3.0-3.9$ was $79.44 \%$, and $2.0-2.9$ was $13.89 \%$. In terms of their motivation to sit for the postgraduate entrance examination, $39.44 \%$ of the students wanted to obtain a higher academic qualification through the examination, $32.78 \%$ wanted to increase their employment opportunities and improve their competitiveness, $22.22 \%$ wanted to further improve of their knowledge structure and level, and only $0.56 \%$ sat for the examination due to family expectations. In addition, there were $5 \%$ who had no clear direction. This may be due to their desire to escape from employment pressure, to continue their campus life, or to blindly follow the trend. Generally, the main purpose of the students to sit for the postgraduate entrance examination was to obtain a higher academic qualification and improve their chances for employment.

\subsection{Postgraduate preference and reason}

In terms of application, the students had clear positioning and overall goals. More than half of the students chose to apply to top public universities while $11.67 \%$ chose basic public universities and $13.33 \%$ had clear ambition to study abroad. Although the number of students from the sample schools admitted to 985 and 211 elite universities over the years were few, $23.33 \%$ of the students still chose to apply for them, possessing a certain elite school complex. For registered majors, more than $70 \%$ of students chose their major or related major, while $26.67 \%$ chose cross-majors.

As for the main factors influencing the choice of schools, given the multiple-choice-question format, this research analyzed by the chi-square goodness of fit test. The goodness-of-fit test showed significance $(\mathrm{chi}=125.510, \mathrm{p}=0.000<0.05)$, meaning that the proportion of choices was significantly different and can be compared by response rate or penetration rate. Specifically, the response rate and penetration rate of 
"school ranking," "I like," and "location of the school" were obviously high; the response rate was between $20 \%$ and $29 \%$, while the penetration rate was between $50 \%$ and $71 \%$. It can be concluded that the selection of schools by the students was determined by location, school ranking, and individual preferences.

\subsection{Exam preparation and plan}

According to the survey, almost half of the students decided on sitting for the postgraduate entrance examination in their early junior year. The survey also revealed that $23.89 \%$ of students had a definite target in their freshman year while fewer students had ideas during their second or senior year, at $13.33 \%$ and $16.11 \%$, respectively. With regard to review time, $42.78 \%$ of students had reviewed for one year prior to sitting for the postgraduate exam. The proportions of half a year and one year were about the same, $30 \%$ and $27.22 \%$, respectively. In terms of hours spent in a day for exam preparation, 3-6 hours accounted for the highest proportion with $31.11 \%$ of students, the proportion of students who spent 6-9 hours a day for preparation was $28.33 \%$, quite a few students spent more than 9 hours $-23.33 \%$, and only $17.22 \%$ of them spent less than 3 hours in preparing for the exam in one day.

\subsection{Difficulties encountered and adjustment made}

It would be conducive as a targeted guidance for schools in future work to learn and understand the difficulties encountered by students. In terms of obstacles, "poor willpower" accounted for the highest proportion, at $49.44 \%$. Data have indicated that the postgraduate exam is a test of a person's patience and perseverance, thus accounting for the importance of "willpower." Besides, time and competence accounted for $21.11 \%$ and $20 \%$, respectively. In regard to the students' feelings toward the postgraduate entrance examination, $20 \%$ of students found it painful, 35\% of students felt it was boring, and additional $30 \%$ of students felt calm, having no strong sense of disgust. In terms of the difficulty of subjects, $33.33 \%$ of students felt that English and professional courses were more difficult, $17.22 \%$ of students chose mathematics, and $6.11 \%$ chose politics. This is because the majority of the postgraduate applicants majored in liberal arts, thus having more advantage in the subject of politics. In that case, fewer students needed to sit for the mathematics exam. In terms of ways to overcome difficulties, the students mainly depended on discussion among schoolmates, accounting for 31.67\%, 12.22\% tended to ask for teachers for help, $17.22 \%$ of them turned to cram schools for help, and other methods accounted for $38.89 \%$.

\subsection{Demands for taking the postgraduate entrance examination}

Students' demands include corresponding conditions, choice of preparation methods, guidance, support from school, etc. Given the multiple-choice-question format, chi-square goodness-of-fit tests were used, and Pareto charts were drawn in order to better analyze the students' needs.

From Table 1, it can be seen that the goodness-of-fit test is significant $\left(\chi^{2}=71.575, \mathrm{P}=0.000<0.05\right)$, meaning that the selection ratio of each item has significant difference, which can be specifically compared through the response rate or penetration rate ${ }^{[5]}$. The response rate and penetration rate for "Environment" were $34.62 \%$ and $85 \%$, respectively. For "Time," the response rate and penetration rate are $29.64 \%$ were $72.78 \%$, respectively. The response rate and penetration rate for "Materials" were $27.6 \%$ and $67.78 \%$, respectively. Evidently, a good learning environment is necessary for postgraduate students, followed by time for learning, and then materials for learning. In order to further understand the key needs of students, a Pareto chart was drawn. It is a graphic embodiment of the " $80 / 20$ principle," indicating that $80 \%$ of the problems are caused by $20 \%$ of the reasons. The options corresponding to the cumulative ratio of $0-80 \%$ are "critical items" and that of $80 \%-100 \%$ are "insignificant items," which are of low importance ${ }^{[5]}$. Based on Figure 1, the cumulative ratio of "Environment" and "Time" is between $25 \%$ and $75 \%$, belonging to 
"critical items," while that of "Materials" and "Others" is between $80 \%$ and $100 \%$, belonging to "insignificant items." Drawing from the chi-square goodness-of-fit test and the Pareto chart, it can be concluded that sufficient preparation time and the learning environment are more important for students taking the postgraduate entrance examination.

Table 1. Students' demands for taking the postgraduate entrance examination

\begin{tabular}{ccccc}
\hline \multirow{2}{*}{ Title } & Item & \multicolumn{2}{c}{ Response } & Penetration rate \\
\cline { 3 - 4 } & & $\mathrm{n}$ & Response rate & $(\mathrm{n}=180)$ \\
\hline \multirow{3}{*}{$\begin{array}{c}\text { Students' demands for taking the } \\
\text { postgraduate exam }\end{array}$} & Time & 131 & $29.64 \%$ & $72.78 \%$ \\
& Environment & 153 & $34.62 \%$ & $85.00 \%$ \\
& Materials & 122 & $27.60 \%$ & $67.78 \%$ \\
& Others & 36 & $8.14 \%$ & $20.00 \%$ \\
\hline Total & & 442 & $100.00 \%$ & $245.56 \%$ \\
\hline
\end{tabular}

Goodness-of-fit test: $\chi^{2}=71.575 ; \mathrm{p}=0.000$

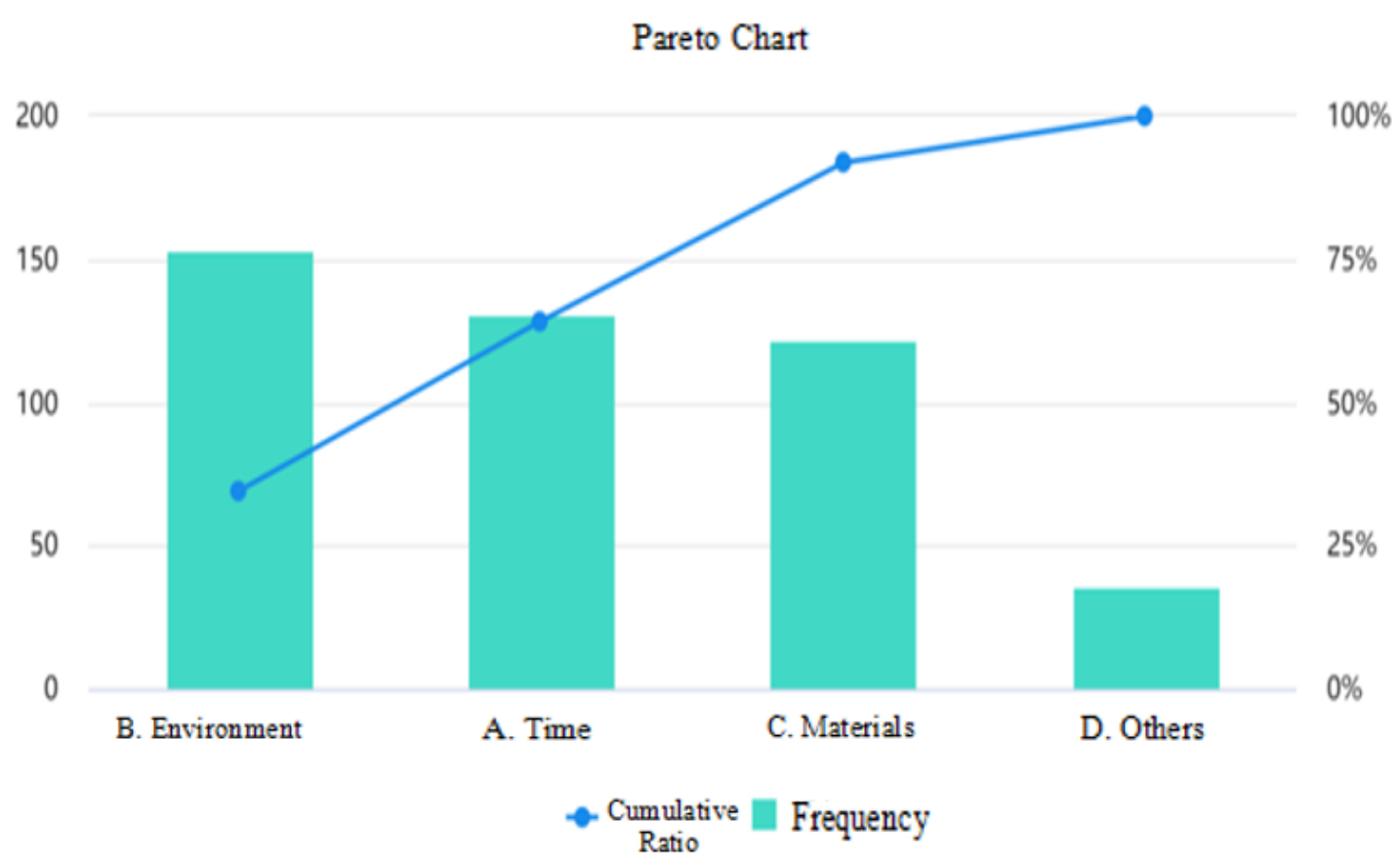

Figure 1. Students' demands for taking the postgraduate entrance examination

In terms of the selection of test preparation methods, it can be seen from Table 2 that the goodness-offit test is significant $\left(\chi^{2}=85.623, \mathrm{P}=0.000<0.05\right)$ and the selection proportion of each item has significant difference. Specifically, the response rate and penetration rate of "Online learning" and "Help from senior students who have experience" were the highest, with response rates of $36.95 \%$ and $23 \%$, respectively as well as penetration rates of $79.44 \%$ and $49.44 \%$, respectively. According to the Pareto chart in Figure 2, the accumulative ratio of "Online learning," "Help from senior students who have experience," and "Attending tutorial classes" is $25 \%$ to $76 \%$, and that of "Consulting the instructors" and "Others" is $80 \%$ to $100 \%$. Drawing from the chi-square goodness-of-fit test and the Pareto chart, it can be concluded that for the test preparation methods, students are more inclined to learn online and consult experienced senior 
students or tutors when necessary.

Table 2. Selection of test preparation methods

\begin{tabular}{ccccc}
\hline \multirow{2}{*}{ Title } & Item & \multicolumn{2}{c}{ Response } & Penetration rate \\
\cline { 3 - 4 } & Help from senior students who & $\mathrm{n}$ & Response rate & \\
\hline & have experience & 89 & $23.00 \%$ & $49.44 \%$ \\
Selections of test \\
$\begin{array}{c}\text { preparation } \\
\text { methods }\end{array}$ & Consulting the instructors & 53 & $13.70 \%$ & $29.44 \%$ \\
& Attending tutorial classes & 61 & $15.76 \%$ & $33.89 \%$ \\
& Online learning & 143 & $36.95 \%$ & $79.44 \%$ \\
\hline & Others & 41 & $10.59 \%$ & $22.78 \%$ \\
\hline
\end{tabular}

Goodness-of-fit test: $\chi^{2}=85.623 ; \mathrm{p}=0.000$

Pareto Chart

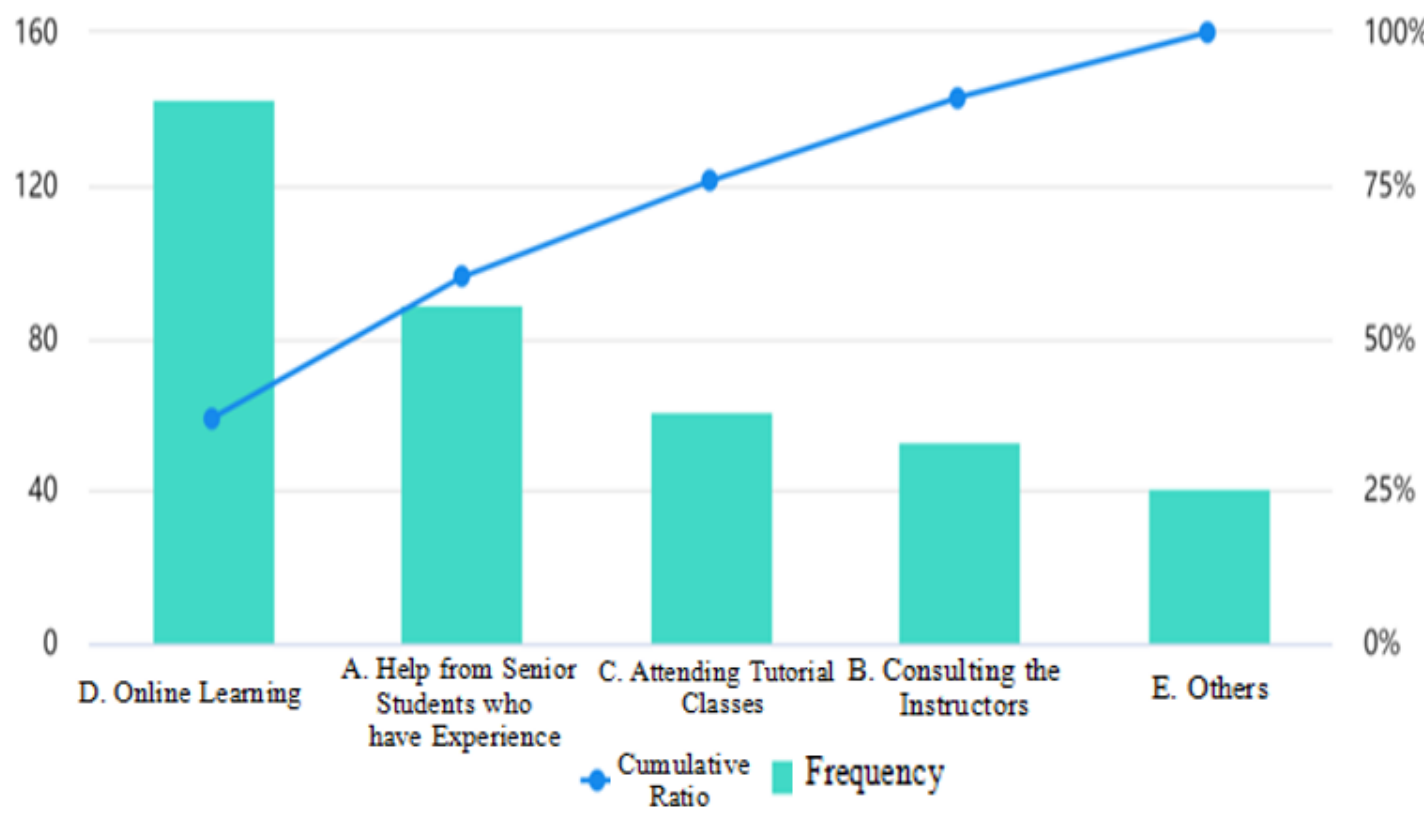

Figure 2. Selection of test preparation methods

From Table 3, it can be seen that the goodness-of-fit test is significant in terms of the guidance needed for exam preparation $\left(\chi^{2}=87.343, \mathrm{P}=0.000<0.05\right)$ and the selection proportion of each item has significant difference. Specifically, "Experience sharing," "Answer skills," and "Interview skills" had the highest response rate and penetration rate, with response rates of $26.23 \%, 23.21 \%$, and $19.43 \%$, respectively as well as penetration rates of $77.22 \%, 68.33 \%$, and $57.22 \%$, respectively. The response rates of other choices were all below 13\%. According to the Pareto chart in Figure 3, the accumulative ratio of "Experience sharing," "Answer skills," "Interview skills," and "Analysis of future employment situation" is between $25 \%$ to $79 \%$, while that of "Psychological counselor" and "Others" is between $80 \%$ to $100 \%$. Drawing from the chi-square goodness-of-fit test and the Pareto chart, it can be concluded that with regard 
to the guidance needed for exam preparation, students require more guidance in experience sharing, answer skills, and interview skills.

Table 3. Guidance needed to prepare for the exam

\begin{tabular}{|c|c|c|c|c|}
\hline \multirow{2}{*}{ Title } & \multirow{2}{*}{ Item } & \multicolumn{2}{|c|}{ Response } & \multirow{2}{*}{$\begin{array}{l}\text { Penetration rate }(\mathrm{n}= \\
180)\end{array}$} \\
\hline & & $\mathrm{n}$ & Response rate & \\
\hline \multirow{6}{*}{$\begin{array}{l}\text { Guidance needed to } \\
\text { prepare for the exam }\end{array}$} & Experience sharing & 139 & $26.23 \%$ & $77.22 \%$ \\
\hline & Interview skills & 103 & $19.43 \%$ & $57.22 \%$ \\
\hline & Psychological counselor & 57 & $10.75 \%$ & $31.67 \%$ \\
\hline & $\begin{array}{l}\text { Analysis of the future } \\
\text { employment situation }\end{array}$ & 68 & $12.83 \%$ & $37.78 \%$ \\
\hline & Answer skills & 123 & $23.21 \%$ & $68.33 \%$ \\
\hline & Others & 40 & $7.55 \%$ & $22.22 \%$ \\
\hline \multicolumn{2}{|c|}{ Total } & 387 & $100.00 \%$ & $215.00 \%$ \\
\hline
\end{tabular}

Goodness-of-fit test: $\chi^{2}=87.343 ; \mathrm{p}=0.000$

\section{Pareto Chart}

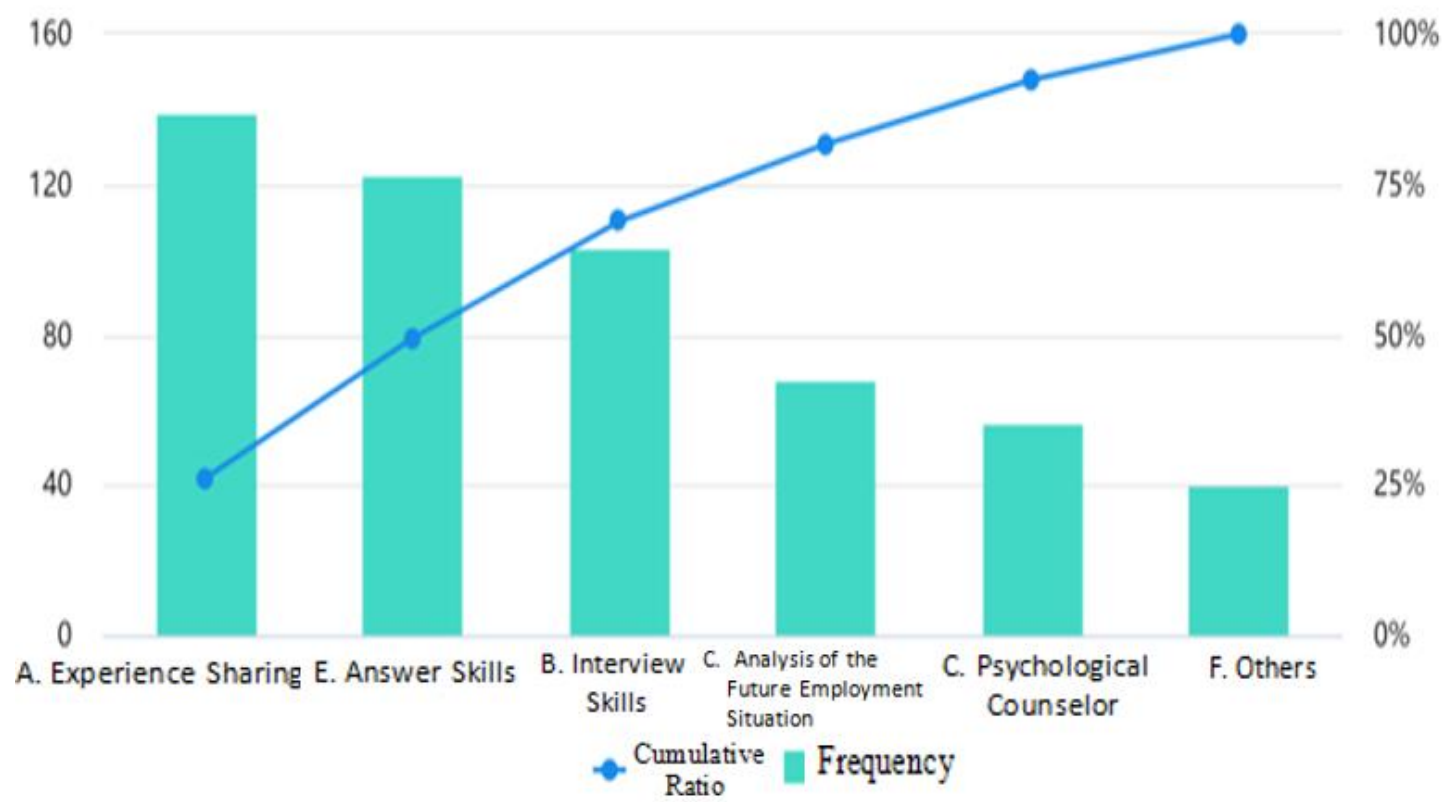

Figure 3. Guidance needed to prepare for the exam

From Table 4, it can be seen that the goodness-of-fit test is significant in terms of support from schools $\left(\chi^{2}=87.343, \mathrm{P}=0.000<0.05\right)$ and the selection proportion of each item has significant difference. Specifically, "Information provision" and "Providing learning environment" had the highest response rate and penetration rate, with response rates of $25.05 \%$ and $28.60 \%$, respectively, and penetration rates of $70.56 \%$ and $80.56 \%$, respectively. Following those are "Organizing lecture" and "Organizing simulation drills before the second examination" with a response rate of about $15 \%$ for both and penetration rate of $42 \%$ to $45 \%$. "Running tutorial class" and "Others" had the lowest demand, with response rates of $9.66 \%$ 
and $5.92 \%$, respectively as well as penetration rates of $27.22 \%$ and $16.67 \%$, respectively. According to the Pareto chart in Figure 4, "Providing learning environment," "Information provision," and "Organizing lecture" are the key needs of students. Drawing from the chi-square goodness-of-fit test and the Pareto chart, it can be concluded that with regard to the support from schools, students expect the schools to provide a comfortable learning environment and exam information.

Table 4. Support from schools

\begin{tabular}{|c|c|c|c|c|}
\hline \multirow{2}{*}{ Title } & \multirow{2}{*}{ Item } & \multicolumn{2}{|c|}{ Response } & \multirow{2}{*}{ Penetration rate $(\mathrm{n}=180)$} \\
\hline & & $\mathrm{n}$ & Response rate & \\
\hline \multirow{6}{*}{$\begin{array}{l}\text { Support from } \\
\text { school }\end{array}$} & Running tutorial class & 49 & $9.66 \%$ & $27.22 \%$ \\
\hline & Organizing lecture & 80 & $15.78 \%$ & $44.44 \%$ \\
\hline & Information provision & 127 & $25.05 \%$ & $70.56 \%$ \\
\hline & Providing learning environment & 145 & $28.60 \%$ & $80.56 \%$ \\
\hline & $\begin{array}{l}\text { Organizing simulation drills } \\
\text { before the second examination }\end{array}$ & 76 & $14.99 \%$ & $42.22 \%$ \\
\hline & Others & 30 & $5.92 \%$ & $16.67 \%$ \\
\hline & Total & 507 & $100.00 \%$ & $281.67 \%$ \\
\hline
\end{tabular}

Goodness-of-fit test: $\chi^{2}=115.852 ; \mathrm{p}=0.000$

\section{Pareto Chart}

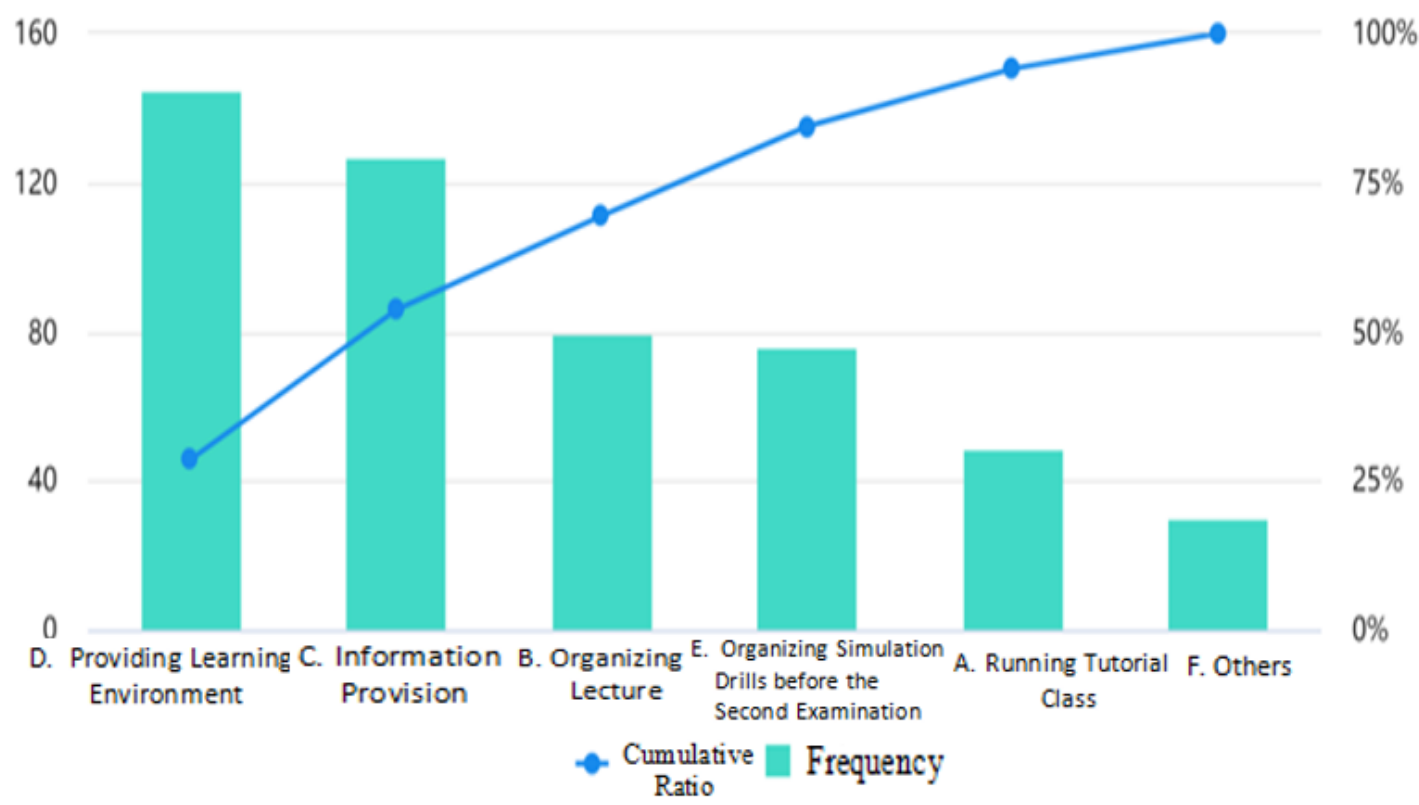

Figure 4. Support from schools 


\section{Conclusion and countermeasures}

\subsection{Conclusion}

\subsubsection{Distinct characteristics and definite motives of students from private colleges in pursuing the postgraduate entrance examination}

Based on the basic information and motivation of the students, there were more female students compared to male students and the students' grade points were mostly above 3.0. Furthermore, $95 \%$ of them possessed definite and clear motivations, which were mainly to gain further knowledge, a higher academic qualification, and a better job after graduation. Compared with public institutions, graduates from private colleges face greater employment pressure and lower employment quality, which greatly accounts for private institutions students' opting to sit for the postgraduate entrance examination.

\subsubsection{Unscientific choice of students from private colleges in pursuing the postgraduate examination}

Based on the analysis of students' preference and reason, it can be appreciated that the sample students focused on their own interest when selecting their specialties. The choice of schools among these students depended more on school ranking, location, and personal preference. It can be seen that they hardly combined any other factors pertaining to the school and lack deeper analysis, just remaining on the periphery. The reason for this may be that private colleges offer less help to students in regard to postgraduate exams and students have no idea of how to select their specialties or schools.

\subsubsection{Students from private colleges require a longer time for exam preparation}

From the analysis of the preparation time, it can be seen that the decision to sit for the postgraduate entrance examination was earlier among the students although the review period took a longer time. Most of them spent 3-9 hours preparing for the exam on a daily basis. This indicates that students from private colleges spend more time preparing for the postgraduate entrance examination. After the college entrance examination, the postgraduate entrance examination is yet another huge test, marked with much difficulty, fierce competition, and long preparation time. Especially for students from private colleges, their knowledge foundation is relatively poor; therefore, more time is required for them to prepare for the examination compared to those from public schools. However, it is because of these differences that private college students realize that "a slow sparrow should make an early start," thereby reinforcing their determination.

\subsubsection{Students from private colleges face more challenges in pursuing the postgraduate entrance examination}

According to the analysis on the challenges faced and adjustments made throughout the process of going for the postgraduate entrance examination, students from private universities would feel discouraged, skeptical about their perseverance and ability, as well as feel that time is insufficient when troubled by difficult subjects; thus, they are more likely to feel bored and even pain psychologically. If they do not receive timely guidance and make adjustments in a timely manner, they easily suffer from inferior learning effect and even psychological problems.

\subsubsection{Students from private colleges lack school support}

The postgraduate entrance examination calls for a high level of mental strength. In spite of students' internal efforts, external support also matters, especially the learning environment. A good learning environment creates a lively atmosphere for learning. Otherwise, there would be inefficient learning. According to the 
analysis of students' demand, students from private colleges require a good learning environment and relevant information about the postgraduate entrance examination. Furthermore, certain guidance in terms of experience sharing, answer skills, and interview skills is indispensable. At present, many private schools are in a situation where there is insufficient attention to the postgraduate entrance examination along with the lack of a good learning environment for the students, in which comprehensive and systematic guidance is being neglected.

\subsection{Countermeasures and suggestions}

\subsubsection{Be assertive and plan scientifically}

The postgraduate entrance examination is a long and arduous process. When deciding to sit for the exam, it is necessary for students to be mentally prepared, maintain a positive attitude, and maintain firm confidence. It also advised that they should formulate a scientific and reasonable review plan that applies to themselves. Meantime, they should ensure each stage follows its own focus and modestly consult teachers or senior students, so that the learning effect can be improved. While dry and dull learning is inevitable, it is encouraged to exchange ideas and discuss learning methods with other students for mutual encouragement and promotion. Students should make effort to ask their seniors who have sat for the exam for advice and learn from them. In times of difficulty, sharing feelings with their schoolmates or teachers would be helpful for students to promote a healthier mentality.

\subsubsection{Guide students based on their aptitudes and implement stratified teaching}

In the first year itself, schools can introduce the postgraduate entrance examination and provide information pertaining to the exam to the students, so that they may gain some understanding about the examination and develop a drive to challenge themselves. In addition to that, schools should not only offer guidance but also relevant details and materials to students who excel and have a definite goal. For one, experimental classes on the most popular majors in the exam can be introduced and equipped with excellent teachers to strengthen the training of related courses, in addition to various other subjects, such as mathematics, English, and political courses. For another, help groups held by senior students who have gone through the postgraduate entrance examination can be set up. Each senior can take on the role of a mentor to guide four or five students to help them prepare for the examination, from teaching materials, learning methods, answer skills, to the points that require attention in the second test. At the same time, each subject is equipped with one or two tutors to dispel students' doubts and confusions encountered in the review process. Other than that, counselors should pay more attention to the students, timely console their psychological fluctuations, and help them to reshape their mentality, thus enabling them to prepare for the examination carefully and in a healthier manner.

\subsubsection{Create a good environment for students}

Schools should take various effective measures to assist students in their preparations for the postgraduate entrance examination. For instance, study rooms can be set up at the library and the main teaching block in order to encourage those students who desire to sit for the examination to group together and learn as well as to provide a good environment for them. Schools can also conduct regular exchange meetings by inviting senior experienced students to share their reflections, setting an example and boosting the motivation of younger students. In turn, students can talk freely about their problems, which would not only help them to release their psychological pressure, but also obtain the guidance and assistance from teachers as well as schoolmates. Last but not least, schools should do the utmost to serve students by meeting the reasonable requirements and providing the latest policy, relevant information, as well as materials pertaining to the 
examination. When conditions permit, schools can also consider setting up a postgraduate entrance examination remedial class.

Facing the postgraduate entrance examination is not a lone effort but joint cooperation among schools, teachers, and students, so as to yield ideal results.

\section{Disclosure statement}

The authors declare that there is no conflict of interest.

\section{References}

[1] Li B, 2007, On the Reason of College Students Postgraduate Entrance Examination Fever from the Employment Difficulty - From the Perspective of Rational Choice of the Goal of Obtaining occupational Status. Journal of Anhui Normal University (Humanities \& Social Sciences), 35(5): 604610.

[2] Cong K, Li X, 2019, Investigation and Analysis on the Influencing Factors of Postgraduate Entrance Examination for College Students. Industrial \& Science Tribune, 18(13): 139-140.

[3] Liu C, 2020, An Analysis of the Current Academic Situation of Postgraduate Students in Private Universities. Intelligence, (21): 31-32, 38.

[4] Yue E, Private Undergraduate Students - The Biggest Sacrifice? Few Achiever in the Postgraduate Examination, Serving as a Perfect Foil. Tencent. https://new.qq.com/rain/a/20210811a07x6900 (accessed on August 11, 2021).

[5] Chow C, 2017, An Analysis of Questionnaire Data - Six Types of Analytical Thinking of SPSS. Publishing House of Electronics Industry. 